\title{
Factors Associated with Anemia among Children Aged 6-23 Months Attending Growth Monitoring at Tsitsika Health Center, Wag-Himra Zone, Northeast Ethiopia
}

\author{
Haile Woldie, ${ }^{1}$ Yigzaw Kebede, ${ }^{2}$ and Amare Tariku' \\ ${ }^{1}$ Department of Human Nutrition, Institute of Public Health, College of Medicine and Health Science, University of Gondar, \\ Gondar, Ethiopia \\ ${ }^{2}$ Department of Epidemiology and Biostatistics, Institute of Public Health, College of Medicine and Health Science, \\ University of Gondar, Gondar, Ethiopia
}

Correspondence should be addressed to Amare Tariku; amaretariku15@yahoo.com

Received 12 February 2015; Revised 24 April 2015; Accepted 10 May 2015

Academic Editor: Christel Lamberg-Allardt

Copyright (C) 2015 Haile Woldie et al. This is an open access article distributed under the Creative Commons Attribution License, which permits unrestricted use, distribution, and reproduction in any medium, provided the original work is properly cited.

Background. Globally, about $47.4 \%$ of children under five are suffering from anemia. In Ethiopia, $60.9 \%$ of children under two years are suffering from anemia. Anemia during infancy and young childhood period is associated with poor health and impaired cognitive development, leading to reduced academic achievement and earnings potential in their adulthood life. However, there is scarcity of information showing the magnitude of iron deficiency anemia among young children in Ethiopia. Therefore, this study aimed at assessing prevalence and associated factors of iron deficiency anemia among children under two (6-23 months). Methods. Institution based cross-sectional study was carried out from March to May, 2014, at Tsitsika Health Center in Wag-Himra Zone, Northeast Ethiopia. Systematic random sampling technique was employed. Automated hemoglobin machine was used to determine the hemoglobin level. Socioeconomic and demographic data were collected by using a pretested and structured questionnaire. Binary logistic regression analysis was used to identify associated factors and odds ratio with 95\% CI was computed to assess the strength of association. Results. Total of 347 children participated in this study. The overall prevalence of anemia was $66.6 \%$. In multivariate logistic regression analysis, male sex (AOR $=3.1$ (95\% CI: 1.60-5.81)), 9-11 months of age (AOR = 9.6 (95\% CI: 3.6125.47)), poor dietary diversity $(\mathrm{AOR}=3.2(95 \% \mathrm{CI}: 1.35-7.38))$, stunting $(\mathrm{AOR}=2.7(95 \% \mathrm{CI}: 1.20-6.05))$, diarrhea $(\mathrm{AOR}=4.9$ $(1.63-14.59))$, no formal education $(\mathrm{AOR}=2.6(95 \% \mathrm{CI}: 1.26-5.27)$ ), early initiation of complementary food $(\mathrm{AOR}=11.1$ ( $95 \% \mathrm{CI}$ : 4.08-30.31)), and lowest wealth quintile $(\mathrm{AOR}=3.0(95 \% \mathrm{CI}: 1.01-8.88)$ ) were significantly associated with anemia. Conclusion. The overall prevalence of anemia among children who aged 6-23 months has sever public health importance in the study area. Integrated efforts need to be prioritized to improve health as well as appropriate infant and young child feeding practice among children under.

\section{Background}

Currently, micronutrient deficiencies are coming to be the most prevalent nutritional deficiencies causing serious developmental problems in the world [1]. Anemia is one of micronutrient deficiencies which have serious public health significance in the world. It is second leading nutritional cause of disability [2-4]. Anemia is an important outcome indicator of poor nutrition and health with its major consequences on socioeconomic development of a population [5]. Anemia can occur at any time and at all stages of the life cycle
[3] but young children and pregnant women are the most at risk segment of the community [1].

Globally, about $47.4 \%$ of children under five are suffering from anemia [6]. In developing countries, it affects $46-66 \%$ of children aged under five years [7]. Africa and Asia are found with sever public health importance of anemia [8]. About $67.6 \%$ of children under five in Africa are suffering from anemia while they are $65.5 \%$ in Southeast Asia [6]. The highest overall prevalence of anemia in children aged under 5 years is recorded in the Western and Central African Region as $75 \%$ [9]. According to the Ethiopian 2011 DHS report, 
the overall prevalence of anemia among children under two years (6-23 months) was $60.9 \%$ [10].

Among children, iron deficiency anemia is consequence of complex interaction of several factors. As different studies claimed that iron deficiency anemia is significantly associated with low birth weight [11], sex [11-14], age [11, 12, 14-16], rural residence, infectious disease (malaria, tuberculosis, intestinal parasitic infestation, and HIV/AIDS) $[15,17]$, undernutrition (stunting, wasting, and underweight) $[13,15,18]$, poor socioeconomic status $[12,14,16,18]$, household food insecurity [12], duration of lactation [18] and poor dietary iron intake [18], poor maternal educational status $[11,14,18]$, and maternal anemia [12].

Anemia during childhood period is strongly associated with poor health and physical development [3, 19], mild and moderate mental retardation $[3,20]$, and poor motor development and control $[16,21]$ leading to reduced academic achievement and work capacity thereby reducing earning potential and damaging national economic growth in the future [19]. Iron deficiency anemia also increases risk of mortality and morbidity from infectious disease [3, 11, 22].

Still anemia with its devastating implication has public health importance among children under five in Africa [23]. In Ethiopia, as part of other African countries, burden of anemia also proves public health significance among children [10]. However, there is scarcity of information showing the burden of anemia and its risk factor among children under two. Therefore, this study was aimed to assess prevalence of anemia and its associated factors among children aged 6-23 months in Wag-Himra zone, Northeast Ethiopia.

\section{Methods}

2.1. Study Area. This study was conducted at Tsitsika Health Center, Ziquala Woreda, Amhara regional state, Northeast Ethiopia. Tsitsika (Woreda capital of Ziquala Woreda) is $730 \mathrm{~km}$ far from Addis Ababa, the capital city of Ethiopia, and founded at 900 meters above sea level. According to the regional finance and economic development projection, the total population of the study area for the year 2014 was 49671. The total numbers of children aged under five and under two years were 6987 and 2473, respectively. Residents of this Woreda largely depend on subsistence farming and producing cereals as main agricultural product. Since 2008, the study area has been implementing community based nutrition intervention program (growth monitoring, nutritional screening, vitamin-A supplementation, outpatient therapeutic feeding program, etc.). At the time of the study, Ziquala Woreda has six health centers and 15 health posts. Growth monitoring targeting children under two years has been carried out by using Weight-for-Age anthropometric index as routine procedure in all health institutions of current study area.

2.2. Study Population and Sampling Techniques. All children aged 6-23 months with mothers/caretakers attending growth monitoring clinic during the study period were included in the study. Those children who did not register from the Health Center logbook for their health status were excluded from the study. Systematic random sampling technique was employed to recruit a total of 347 children. The total sample size was determined by using the formula to estimate a single population proportion with the following assumptions: population proportion $(P)$, that is, $60.91 \%$ taken from Ethiopian 2011 DHS report as prevalence of anemia among children aged 6-23 months, 95\% confidence level, and 5\% margin of error. Then, the final sample size 366 was obtained. The sampling interval was calculated from the 2013 growth monitoring registration book of the Health Center. The number of children aged 6-23 months and participated for growth monitoring during calendar year of March to May/2013 was taken as 763 from the logbook. Children who have no record regarding their morbidity status on the registration book were not included in the study. Sampling interval was determined by $763 / 366=2.01 \approx 2$; then, lottery method was employed to select starting or first sample in the study. The procedure continued until the required sample size was obtained.

2.3. Data Collection Tools and Procedures. Socioeconomic and demographic characteristics of the family and child, feeding practice, health care utilization, and child morbidity status (within two weeks before data collection) were collected by using a pretested and structured questionnaire through interviewing of the mother/caretakers of the child. Hemoglobin level of the child was measured from capillary blood and one drop of capillary blood was carefully collected from the middle finger of the child by finger prick. Strict aseptic technique and a separate lancet for each child were employed. Automated hemoglobin machine made from Germany with model $\mathrm{kx}-21$ and serial number b-0839Model was used to determine the hemoglobin concentration and the result was expressed in $\mathrm{g} / \mathrm{dL}$ and the presence and severity of anemia were determined according to age based criteria of WHO cut-off point. For children aged 6-24 months who have hemoglobin level $>11 \mathrm{~g} / \mathrm{dL}$, they were considered as nonanemic, $10.0-10.9 \mathrm{~g} / \mathrm{dL}$ as mildly anemic, $7-9.9 \mathrm{~g} / \mathrm{dL}$ moderately anemic, and $<7 \mathrm{~g} / \mathrm{dL}$ as severely anemic [24].

Nutritional status of the child was assessed by taking anthropometric body measurement of the child. Length of a child was measured in a recumbent position to the nearest $0.1 \mathrm{~cm}$ by using a board with an upright wooden base and a movable headpiece, on a flat surface. Weight measurement of a child was taken by a Salter scale (model-2356S) with the calibration of $100 \mathrm{~g}$ unit. It is designed and manufactured under the authority and recognition of the United Nations Children's Fund (UNICEF). The scale was adjusted to zero before weighing every child and measurement was recorded to the nearest $0.1 \mathrm{~kg}$. Each measurement was repeated and the mean value was calculated and recorded on the questionnaire. All children were without any shoes during the measurement.

Age of child was determined by two methods: for 81 children aged between 12-23 months, their birth date was extracted from the immunization card; while for 266 children without immunization card and who aged under 12 months, their age was determined by using information given by the mother/female caretaker of the child. The three 
standard indices (Length-for-Age, Weight-for-Length, and Weight-for-Age) were analyzed by ANTHRO software and used to determine the nutritional status of children. Each of the three measurements was expressed in standard deviation units of $Z$-score from the median of WHO-2006, standard population [25]. Children with a measurement $<-2$ of $Z$ score were determined as stunted for Length-for-Age, wasted for Weight-for-Length, and underweight for Weight-forAge. Information related to morbidity status of the child (intestinal parasite, diarrhea, malaria, and upper respiratory tract infection) before two weeks was captured by looking up the health centre logbook.

2.4. Measurement of Dietary Diversity Score. Dietary diversity scores of a child were determined by using WHO and "indicators for assessing infant and young child feeding practices" minimum dietary diversity for children age 623 months and by employing $24 \mathrm{hrs}$ recall method. Mothers or female care takers were asked to report all food items and beverages given to the child during the previous day of the survey. Then, all food items and beverages consumed by the child were categorized into seven food groups as (1) grains, roots, and tubers, (2) legumes and nuts, (3) dairy products, (4) flesh foods, (5) eggs, (6) vitamin-A rich fruits and vegetables, and (7) other fruits and vegetables [26]. Using dietary diversity score 4 (minimum dietary diversity score) as cut-off point, a child was defined as having "poor dietary diversity" if he/she consumed less than 4 food groups while having "good dietary diversity" if he/she had 4 or more food groups.

2.5. Determination of Wealth Index. The wealth index was used in the study and constructed from the data collected in the household questionnaire. The standardized tool for measurement of wealth index was adopted from Ethiopian DHS-2011 [10]. This index consist of seven selected household asset data, that is, availability of electric city, television, refrigerator, mobile telephone, nonmobile telephone, a bed with cotton/sponge/spring mattress, and electric mittade (local name for electric stove or oven), and via a principal components analysis. The wealth index was divided into five categories (lowest, second, middle, fourth, and highest).

2.6. Data Quality Control. Two-day intensive training was given for data collectors and supervisors regarding study objective, interview techniques, anthropometric measurements, and ethical issues during data collection. Pretest without hemoglobin level determination was done among 5\% of the total sample size in the nearest health postproviding growth monitoring service before three days of the actual data collection in order to sort out language barriers and contextual difference on the structured questionnaires. Questionnaire was checked daily for accuracy, consistency, and completeness by supervisor. Furthermore, the supervisors and the principal investigator give feedback and correction regarding the collected data on daily basis to the data collectors.
2.7. Data Processing and Analysis. Data was cleaned, coded, and entered using EPI-INFO version 3.5.3 and exported to SPSS version 16 for analysis. Bivariate analysis was done to see the association of each independent variable with the outcome variable (anemia status). Those independent variables having $P$ value less than 0.2 in the bivariate analysis were entered into the multivariate analysis to determine the effect of each explanatory variable on outcome variable and to control the possible effect of confounders. Odds ratio with 95\% confidence level was used to determine the strength of association. In the multivariate analysis, independent variables with $P$ value $\leq 0.05$ were considered as significant.

2.8. Ethical Consideration. Ethical approval was obtained from Institutional Review Board of University of Gondar. Each mother/caretaker was informed about the objective of the study and written informed consent was secured before questionnaire administered. A child with a confirmed anemia was referred to the concerned body in the Health Center.

\section{Results}

3.1. Socioeconomic and Demographic Characteristics of a Child and Family. A total of 347 children aged 6-23 months with their mothers/caretakers were included in the study giving response rate of $97 \%$. Fourteen percent of mothers/caretakers of children had no formal education. Eighty percent of children were living with both parents and $55.9 \%$ had one sibling aged under five years. Nineteen percent of families were at the lowest level of wealth quintile range and $10.4 \%$ were at the highest one (Table 1).

3.2. Feeding Practice and Nutritional Status of Children. Only one child was found without history of ever breast feed and $88.2 \%$ of children were found with history of current breast feeding status during the interview. About 20.5\% of children had early introduction of complementary foods while $25.1 \%$ were found with history of cow's milk consumption before 12 months of their age. Eighty five percent of children had poor dietary diversity scores. Nearly $24 \%$ of children were stunted (Table 2).

3.3. Morbidity and Health Care Related Characteristics of the Child. About 59.4\% of children were born at home. Regarding the morbidity status, $14.4 \%$ were with malaria infection and $14.7 \%$ of children had diarrhea in the last two weeks (Table 3).

3.4. Prevalence of Anemia among Children Aged 6-23 Months. The overall prevalence of anemia was $66.6 \%$. Burden was higher among males with the magnitude of $55.4 \%$. Among the four age groups, the highest prevalence was recorded in the age group of 9-11 months (79.6\%), followed by 6-8 months (69.2\%).

3.5. Factors Associated with Anemia among Children Aged 623 Months. The result of both bi- and multivariate analyses revealed that sex of the child, age, history of diarrhea before 
TABLE 1: Socioeconomic and demographic characteristics of the family and children aged 6-23 months attending growth monitoring at Tsitsika Health Center, Northeast Ethiopia $(n=347)$.

\begin{tabular}{|c|c|c|}
\hline Background characteristics & Frequencies & Percent (\%) \\
\hline \multicolumn{3}{|l|}{ Sex of the child } \\
\hline Male & 171 & 49.3 \\
\hline Female & 176 & 50.7 \\
\hline \multicolumn{3}{|l|}{ Age of the child (in months) } \\
\hline $6-8$ months & 91 & 26.2 \\
\hline 9-11 months & 93 & 26.8 \\
\hline $12-17$ months & 100 & 28.8 \\
\hline $18-23$ months & 63 & 18.2 \\
\hline \multicolumn{3}{|l|}{ Respondent relation to the child } \\
\hline Mother & 335 & 96.5 \\
\hline Other & 12 & 3.5 \\
\hline \multicolumn{3}{|l|}{ Marital status of the mother/caretaker } \\
\hline Single & 36 & 10.4 \\
\hline Married & 306 & 88.2 \\
\hline Other ${ }^{*}$ & 5 & 1.4 \\
\hline \multicolumn{3}{|l|}{$\begin{array}{l}\text { Educational status of the } \\
\text { mother/caretaker }\end{array}$} \\
\hline No formal education & 140 & 40.3 \\
\hline Primary education & 114 & 32.9 \\
\hline$\geq$ Secondary education & 93 & 26.8 \\
\hline \multicolumn{3}{|l|}{$\begin{array}{l}\text { Employment status of the } \\
\text { mother/caretaker }\end{array}$} \\
\hline Housewife & 266 & 76.7 \\
\hline Civil servant & 27 & 7.8 \\
\hline Farmer & 27 & 7.8 \\
\hline Merchant & 11 & 3.2 \\
\hline Other** & 16 & 4.6 \\
\hline \multicolumn{3}{|l|}{ Father educational status } \\
\hline No formal education & 78 & 22.7 \\
\hline Primary education (1-8) & 147 & 42.4 \\
\hline$\geq$ Secondary education and above & 121 & 34.9 \\
\hline \multicolumn{3}{|l|}{ Father employment status } \\
\hline Farmer & 149 & 42.9 \\
\hline Civil servant & 74 & 21.3 \\
\hline Merchant & 59 & 17.0 \\
\hline Private employed & 47 & 13.5 \\
\hline Other & 18 & 5.2 \\
\hline \multicolumn{3}{|l|}{ Birth order of the child } \\
\hline 1st & 65 & 18.7 \\
\hline 2nd & 74 & 21.3 \\
\hline $3 \mathrm{rd}$ & 69 & 19.9 \\
\hline 4th and above & 139 & 40.1 \\
\hline \multicolumn{3}{|l|}{ Living arrangement of the child } \\
\hline Living with both parents & 305 & 87.9 \\
\hline Living with mother only & 38 & 10.9 \\
\hline Living with grandparents & 4 & 1.2 \\
\hline
\end{tabular}

TABLE 1: Continued.

\begin{tabular}{lcc}
\hline Background characteristics & Frequencies & Percent (\%) \\
\hline Number of siblings aged $<5$ years & & \\
0 & 150 & 43.2 \\
1 & 194 & 55.9 \\
$\geq 2$ & 3 & 0.9 \\
Number of children in the family & & \\
$2-3$ & 96 & 27.7 \\
$4-6$ & 235 & 67.7 \\
$\geq 7$ & 16 & 4.6 \\
Household wealth index & & \\
Lowest & 67 & 19.3 \\
Second & 78 & 22.5 \\
Middle & 108 & 31.1 \\
Fourth & 58 & 16.7 \\
Highest & 36 & 10.4 \\
\hline
\end{tabular}

* divorced, widowed, and separated.

${ }^{* *}$ Student and house servant.

two weeks, maternal educational status, dietary diversity, introduction of complementary foods, stunting, and household wealth quintile were significantly associated with the anemia (Figure 2 and Table 4).

\section{Discussion}

The result of this study revealed that $66.6 \%$ of children were anemic (95\% CI: 0.619-0.713). The result is slightly higher than 2011 Ethiopian DHS report, 60.9\% [10], and Bangladesh, $60 \%$ [27]. But the finding is lower than study report in Nepal, 69\% [28], and Ghana, 84.3\% [29]. This could be because, in developing countries, complementary foods for children are mostly porridges made of locally available staple cereals [30]. Cereals are known to be rich in phytates, which are nutrients causing poor bioavailability of iron. Similarly, staple food in the study area is cereal based given that children in the current study area share the same risk with other developing countries. Approximately 36\% of children were with history of early and late introduction of complementary foods. Both carries risks contributing to persistent young child malnutrition [30]. Both practices are well known to cause anemia among young children. The current study area (Figure 1) is one of chronical foods in secured area in the region. This household food insecurity might hinder child from obtaining adequate and appropriate complementary food due to poor household food purchasing power.

Male children were 3.1 times more likely to be anemic as compared to females ( $\mathrm{AOR}=3.1$ (95\% CI: $1.60-5.81)$ ). This finding is similar with study reports in Ghana [29] and Bangladesh [27]. Other studies conducted in Tanzania [31] and Brazil [32] found that sex difference did not show association with anemia. The possible explanation for this discrepancy could be due to sate of rapid growth of male children in the first months of life which increases their micronutrient requirement including iron [33]. If this physiological state is not compensated with appropriate and iron 
TABLE 2: Feeding practice and nutritional status of children aged 6-23 months attending growth monitoring clinic at Tsitsika Health Center, Northeast Ethiopia $(n=347)$.

\begin{tabular}{|c|c|c|}
\hline Background characteristics & Frequencies & Percent $(\%$ \\
\hline \multicolumn{3}{|l|}{ Ever breast feed } \\
\hline Yes & 346 & 99.7 \\
\hline No & 1 & 0.3 \\
\hline \multicolumn{3}{|l|}{ Current breast feeding status } \\
\hline Yes & 306 & 88.2 \\
\hline No & 41 & 11.8 \\
\hline \multicolumn{3}{|l|}{ Introduction of complementary foods } \\
\hline Early (<6 months) & 71 & 20.5 \\
\hline Timely (6-8 months) & 223 & 64.3 \\
\hline Late ( $\geq 9$ months) & 53 & 15.3 \\
\hline \multicolumn{3}{|l|}{ History of pica consumption } \\
\hline Yes & 87 & 25.0 \\
\hline No & 254 & 75.0 \\
\hline \multicolumn{3}{|l|}{ History of cow's milk consumption } \\
\hline Yes & 88 & 25.1 \\
\hline No & 259 & 74.9 \\
\hline \multicolumn{3}{|l|}{ Meat consumption/week } \\
\hline Yes & 89 & 25.6 \\
\hline No & 258 & 74.4 \\
\hline \multicolumn{3}{|l|}{ Fruit consumption per week } \\
\hline Yes & 101 & 29.1 \\
\hline No & 246 & 70.9 \\
\hline \multicolumn{3}{|l|}{ Dietary diversity score } \\
\hline Poor* & 296 & 85.3 \\
\hline Good $^{* *}$ & 51 & 14.7 \\
\hline \multicolumn{3}{|l|}{ Length-for-Age } \\
\hline Stunted $(<-2-Z$-score $)$ & 82 & 23.6 \\
\hline Not Stunted $(>-2-Z$-score $)$ & 265 & 76.4 \\
\hline \multicolumn{3}{|l|}{ Weight-for-Length } \\
\hline Wasted $(<-2-Z$-score $)$ & 54 & 15.6 \\
\hline Not Wasted $(>-2-Z$-score $)$ & 293 & 84.4 \\
\hline \multicolumn{3}{|l|}{ Weight-for-Age } \\
\hline Underweight $(<-2-Z$-score $)$ & 61 & 17.5 \\
\hline Not underweight $(>-2-Z$-score $)$ & 286 & 82.5 \\
\hline
\end{tabular}

Note: ${ }^{*}$ child received foods from $<3$ food groups in the previous $24 \mathrm{hrs}$. ${ }^{* *}$ Child who received foods from $\geq 4$ food groups in the previous $24 \mathrm{hrs}$.

rich complementary foods at this critical stage, risk of iron deficiency anemia will be higher among male children as compared to their counterpart.

Children in the age group of 6-8, 9-11, and 12-17 months were 3.5 times $(\mathrm{AOR}=3.5$ (95\% CI: $1.46-8.26)$ ), 9.6 times $(\mathrm{AOR}=9.6(95 \% \mathrm{CI}: 3.61-25.47))$, and 2.9 times $(\mathrm{AOR}=2.9$ (95\% CI: 1.23-6.75)) more likely to be anemic than children in the age range of 18-23 months, respectively. This could be because prenatal iron store depletion is highest starting at six months of age [34]. In addition, it may be due to poor maternal iron reserve during pregnancy. It is known that
TABLE 3: Morbidity and health care related characteristics of children aged 6-23 months attending growth monitoring clinic at Tsitsika Health Center, Northeast Ethiopia, $2014(n=347)$.

\begin{tabular}{|c|c|c|}
\hline Background characteristics & Frequencies & Percent (\%) \\
\hline \multicolumn{3}{|l|}{ Birth place of the child } \\
\hline Home & 206 & 59.4 \\
\hline Health institution & 141 & 40.6 \\
\hline \multicolumn{3}{|c|}{ Immunization status of the child } \\
\hline Partial immunization & 246 & 70.9 \\
\hline Full immunization & 101 & 29.1 \\
\hline \multicolumn{3}{|l|}{ ITN* $^{*}$ utilization } \\
\hline Yes & 139 & 40.1 \\
\hline No & 208 & 59.9 \\
\hline \multicolumn{3}{|l|}{ History of malaria infection } \\
\hline Yes & 50 & 14.4 \\
\hline No & 297 & 85.6 \\
\hline \multicolumn{3}{|c|}{$\begin{array}{l}\text { History of intestinal parasite in the past } 2 \\
\text { weeks }\end{array}$} \\
\hline Yes & 11 & 3.2 \\
\hline No & 336 & 96.8 \\
\hline \multicolumn{3}{|c|}{ History of diarrheal in the past 2 weeks } \\
\hline Yes & 51 & 14.7 \\
\hline No & 296 & 85.3 \\
\hline \multicolumn{3}{|c|}{ History of URTIs ${ }^{* *}$ in the past 2 weeks } \\
\hline Yes & 7 & 2.0 \\
\hline No & 340 & 98.0 \\
\hline
\end{tabular}

Note: ${ }^{*}$ ITN: insecticide threatened bed nets.

${ }^{* *}$ URTIs: upper respiratory tract infections.

the anemic pregnant mothers are more likely to give birth of child with poor iron stores [12].

Children with early ( $<6$ months) and late ( $\geq 9$ months) introduction of complementary foods were 11.1 times $(\mathrm{AOR}=$ 11.1 (95\% CI: $4.08-30.31)$ ) and 4.3 times (AOR $=4.3(95 \%$ CI: 1.78-10.18)) more likely to be anemic than children with timely initiation of complementary food, respectively. It is evident that most digestive enzymes are inadequate until the first six months of age [35] and introducing liquid or solid food during this time causes interference with the absorption of iron in the breast milk [36]. Early exposure of infants (before six months of age) to microbial pathogens due to complementary foods increases the risk of infection for diarrheal disease, thereby malabsorption [37]. Breast milk has minimal iron to fulfill nutritional requirement of growing infant [38], given that providing breast milk alone coupled with rapid iron depletion beyond six months also increases risk of anemia for younger infant.

Those children with poor dietary diversity score were near to three times more likely to be anemic than children with good dietary diversity scores $(\mathrm{AOR}=3.2(95 \% \mathrm{CI}$ : 1.35-7.38)). Cereal based monotonous diets (undiversified diet) are known to cause micronutrient deficiency including anemia [39]. It is also evidenced that dietary diversity is proxy indicator for micronutrient adequacy of diet [40]. 
TABLE 4: Factors associated with anemia among children aged 6-23 months attending growth monitoring clinic at Tsitsika Health Center, Northeast Ethiopia, $(n=347)$.

\begin{tabular}{|c|c|c|c|c|}
\hline \multirow{2}{*}{ Background characteristics } & \multicolumn{2}{|c|}{ Anemia status of children } & \multirow{2}{*}{ COR (95\%: CI) } & \multirow{2}{*}{ AOR (95\%: CI) } \\
\hline & Yes & No & & \\
\hline \multicolumn{5}{|l|}{ Sex } \\
\hline Male & 131 & 40 & $2.5(1.57-3.95)^{*}$ & $3.1(1.60-5.81)^{*}$ \\
\hline Female & 100 & 76 & 1.00 & 1.00 \\
\hline \multicolumn{5}{|l|}{ Age } \\
\hline 6-8 months & 63 & 28 & $2.1(1.05-3.98)^{* *}$ & $3.5(1.46-8.26)^{*}$ \\
\hline 9-11 months & 74 & 19 & $3.5(1.75-7.17)^{*}$ & $9.6(3.61-25.47)^{*}$ \\
\hline 12-17 months & 61 & 39 & $1.4(0.75-2.69)$ & $2.9(1.23-6.75)^{* *}$ \\
\hline $18-23$ months & 33 & 30 & 1.00 & 1.00 \\
\hline \multicolumn{5}{|l|}{ Introduction of complementary foods } \\
\hline$<6$ months & 65 & 6 & $8.5(3.53-20.42)^{*}$ & $11.1(4.08-30.31)^{*}$ \\
\hline$\geq 9$ months & 41 & 12 & $2.7(1.34-5.37)^{*}$ & $4.3(1.78-10.18)^{*}$ \\
\hline $6-8$ months & 125 & 98 & 1.00 & 1.00 \\
\hline \multicolumn{5}{|l|}{ Dietary diversity } \\
\hline Poor & 208 & 88 & $2.9(1.57-5.27)^{*}$ & $3.2(1.35-7.38)^{*}$ \\
\hline Good & 23 & 28 & 1.00 & 1.00 \\
\hline \multicolumn{5}{|l|}{ Length-for-Age } \\
\hline Stunted & 70 & 12 & $3.8(1.95-7.29)^{*}$ & $2.7(1.20-6.05)^{* *}$ \\
\hline Not stunted & 161 & 104 & 1.00 & 1.00 \\
\hline \multicolumn{5}{|l|}{ History of diarrhoea before 2 weeks } \\
\hline Yes & 47 & 5 & $5.5(2.13-14.31)^{*}$ & $4.9(1.63-14.59)^{*}$ \\
\hline No & 185 & 111 & 1.00 & 1.00 \\
\hline \multicolumn{5}{|l|}{ Educational level of the mother } \\
\hline No formal education & 109 & 31 & $3.4(1.947-6.083)^{*}$ & $2.6(1.26-5.27)^{* *}$ \\
\hline Primary education & 75 & 39 & $1.9(1.07-3.30)^{* *}$ & $1.8(0.83-3.71)$ \\
\hline Secondary education and above & 47 & 46 & 1.00 & 1.00 \\
\hline \multicolumn{5}{|l|}{ HH wealth index } \\
\hline Lowest & 53 & 14 & $3.8(1.57-9.12)^{*}$ & $3.0(1.01-8.88)^{* *}$ \\
\hline Second & 55 & 23 & $2.4(1.06-5.40)^{* *}$ & $2.8(1.02-7.81)^{* *}$ \\
\hline Middle & 73 & 35 & $2.1(0.97-4.50)$ & $1.2(0.46-3.28)$ \\
\hline Fourth & 32 & 26 & $1.2(0.54-2.83)$ & $0.9(0.33-2.52)$ \\
\hline Highest & 18 & 18 & 1.00 & 1.00 \\
\hline
\end{tabular}

Note: $P$ value $*<0.01$, and $* *=0.01-0.05$.

$\mathrm{HH}$ : household.

Children with history of diarrhea before two weeks of the study were 4.9 times more likely to be anemic than children without diarrhea $(\mathrm{AOR}=4.9(1.63-14.59))$. This finding is consistent with study reports in Indonesia $[41,42]$ and Brazil [32]. This could mainly operate through loss of appetite and malabsorption from diarrhea which in turn increases likelihood of developing anemia.

Stunted children were 2.7 times more likely to be anemic than their counterpart $(\mathrm{AOR}=2.7$ (95\% CI: $1.20-6.05))$. This finding is similar to studies conducted in Bangladesh [27], Brazil [43], and Burma [44]. This is could be because undernourished children are often anemic [43], low hemoglobin level has compromising effect of the linear growth [45], and coexisting of other micronutrient deficiencies and stunting may increase the development of anemia by a synergism association. But the current study cannot provide cause and effect relationship between stunting and iron deficiency anemia.

Children of mothers with no formal education were 2.6 times more likely to be anemic than children of mother with secondary and above education level $(\mathrm{AOR}=2.6$ (95\% CI: 1.26-5.27)). This finding is similar to study conducted in Kenya [14], Ghana [39], and Bangladesh [28]. But a study conducted in Timor-Lest [46] reported that maternal educational status was inversely associated with their children's nutritional status. Children of mothers with secondary education had significantly lower mean hemoglobin concentration than mothers with primary and no education. Moreover, mothers' 


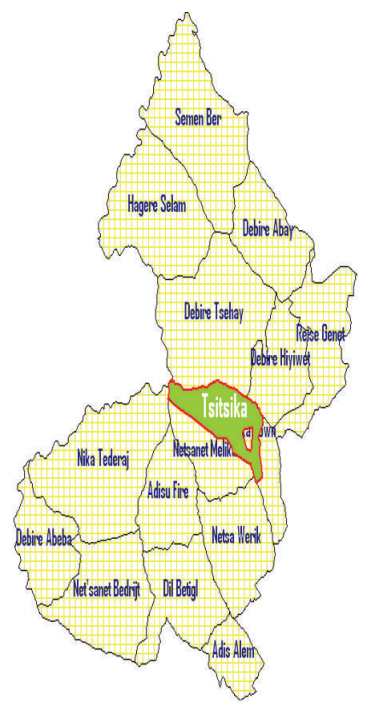

Figure 1: Map of Ziquala Woreda (study area), Northeast Ethiopia.

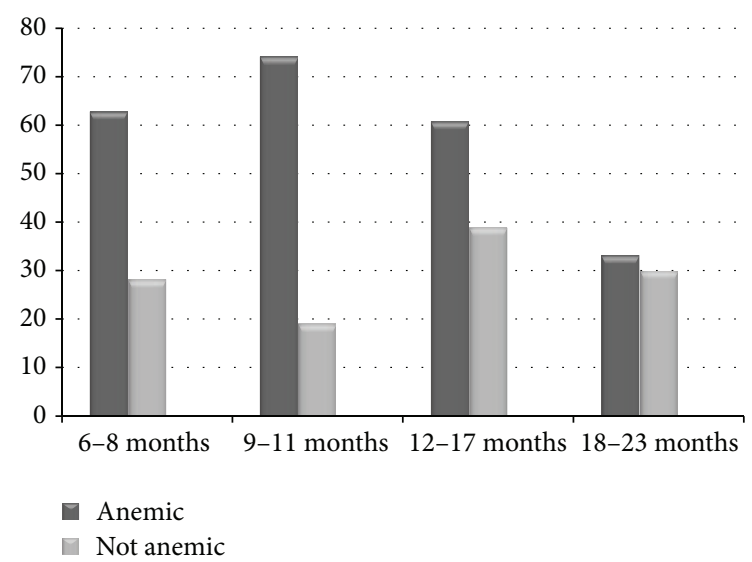

Figure 2: Number of children (6-23 months) with anemia by age category.

level of education may positively influence practices related to the health care and feeding practice of their children. Educated mothers are more conscious of their children's health and introducing scientifically proved feeding practices, which help to improve their children nutritional status [28]. It is also confirmed that, maternal education is strong predictor for nutritional outcomes of children [39].

Children from families of lowest wealth quintiles were three times more likely to be anemic than children from highest wealth quintile ( $\mathrm{AOR}=3.0$ (95\% CI: 1.01-8.88)). The finding of the current study is in line with studies conducted in Ghana [39], Brazil [33], and Bangladesh [28]. Poor household economic status might result in loss of power to purchase diversified and nutrient rich food and secure the household per capita food availability. Other studies also reveal that poor household economic status is associated with household food insecurity [22]. In turn, household food insecurity is strong determinant factor for undernutrition including iron deficiency anemia $[12,47]$.
Some limitations of the study should be noted and taken into consideration. Cross-sectional nature of this study did not reveal causal links between independent variables and iron deficiency anemia. Anemia status from the study group was determined by using the hemoglobin level but not by using the latest test indicators like serum ferritin.

\section{Conclusion}

Burden of anemia among children aged 6-23 months in the study area is higher and it has severe public health significance according to the WHO cut-off points. Stunting, mother with no formal education, lowest wealth quintiles, having diarrhea before two weeks, poor dietary diversity scores, early and late introduction of complementary foods, and sex and age of the child were significantly associated with anemia. Well integrated interventions to improve the health status and infant and young child feeding practices need to be prioritized to prevent deficiency of anemia targeting children aged under two years of age.

\section{Conflict of Interests}

The authors declare that they have no competing interests.

\section{Authors' Contribution}

Haile Woldie designed the study, carried out statistical analysis, and thesis writes up process and manuscript preparation. Yigzaw Kebede and Amare Tariku participated in proposal writing, reviewing, and approval of the thesis and manuscript writing. Haile Woldie, Yigzaw Kebede, and Amare Tariku contributed equally to this work.

\section{Acknowledgments}

The authors would like to express their sincere gratitude to those children and their mother/caretaker for their willingness and positive cooperation for being part of the study. The authors' heartfelt gratitude will also go to the ENGIEN/JHPIEGO, Ethiopia, for the financial support of this study.

\section{References}

[1] R. Aikawa, N. C. Khan, S. Sasaki, and C. W. Binns, "Risk factors for iron-deficiency anaemia among pregnant women living in rural Vietnam," Public Health Nutrition, vol. 9, no. 4, pp. 443448, 2006.

[2] World Health Organization, WHO Vitamin and Mineral Nutrition/Anemia, 2011.

[3] E. McLean, M. Cogswell, I. Egli, D. Wojdyla, and B. De Benoist, "Worldwide prevalence of anaemia, WHO Vitamin and Mineral Nutrition Information System, 1993-2005," Public Health Nutrition, vol. 12, no. 4, pp. 444-454, 2009.

[4] S. Awasthi, R. Das, T. Verma, and S. Vir, "Anemia and undernutrition among preschool children in Uttar Pradesh, India," Indian Pediatrics, vol. 40, no. 10, pp. 985-990, 2003. 
[5] World Health Organization, Global Burden of Diseases 2004 Update, World Health Organization, Geneva, Switzerland, 2008.

[6] B. D. Benoist, E. McLean, I. Egll, M. Cogswell, and D. Wojdyla, Worldwide Prevalence of Anemia 1993-2005: WHO Global Database on Anemia, World Health Organization, 2008.

[7] B. Lozoff and M. K. Georgieff, "Iron deficiency and brain development," Seminars in Pediatric Neurology, vol. 13, no. 3, pp. 158-165, 2006.

[8] WHO, Worldwide Prevalence of Anemia 1993-2005: WHO Global Database on Anemia, World Health Organization, Geneva, Switzerland, 2008.

[9] S. Villalpando, T. Shamah-Levy, C. I. Ramírez-Silva, F. MejíaRodríguez, and J. A. Rivera, "Prevalence of anemia in children 1 to 12 years of age: results from a nationwide probabilistic survey in Mexico," Salud Pública de México, vol. 45, no. 4, pp. S490S498, 2003.

[10] Central Statistical Authority (Ethiopia) and ORC Macro, Ethiopia Demographic and Health Survey 2011, Central Statistical Authority, Addis Ababa, Ethiopia; ORC Macro, Calverton, Md, USA, 2011.

[11] E. Pollitt, "Early iron deficiency anemia and later mental retardation," The American Journal of Clinical Nutrition, vol. 69, no. 1, pp. 4-5, 1999.

[12] S.-R. Pasricha, J. Black, S. Muthayya et al., "Determinants of anemia among young children in rural India," Pediatrics, vol. 126, no. 1, pp. e140-e149, 2010.

[13] G. Egbi, M. Steiner-Asiedu, F. S. Kwesi et al., "Anaemia among school children older than five years in the Volta Region of Ghana," Pan African Medical Journal, vol. 17, no. 1, article 10, 2014.

[14] O. Ngesa, H. Mwambi, and J. A. Stoute, "Prevalence and risk factors of anaemia among children aged between 6 months and 14 years in Kenya," PLoS ONE, vol. 9, no. 11, Article ID el13756, 2014.

[15] A. Shet, S. Mehta, N. Rajagopalan et al., "nemia and growth failure among HIV-infected children in India: a retrospective analysis," BMC Pediatrics, vol. 9, article 37, 2009.

[16] M. A. Cardoso, K. K. G. Scopel, P. T. Muniz, E. Villamor, and M. U. Ferreira, "Underlying factors associated with anemia in amazonian children: a population-based, cross-sectional study," PLoS ONE, vol. 7, no. 5, Article ID e36341, 2012.

[17] A. Desalegn, A. Mossie, L. Gedefaw, and C. M. Schooling, "Nutritional iron deficiency anemia: magnitude and its predictors among school age children, southwest ethiopia: a community based cross-sectional study," PLOS ONE, vol. 9, no. 12, Article ID el14059, 2014.

[18] S. Villalpando, T. Shamah-Levy, C. I. Ramírez-Silva, F. MejíaRodríguez, and J. A. Rivera, "Prevalence of anemia in children 1 to 12 years of age. Results from a nationwide probabilistic survey in Mexico," Salud Pública de México, vol. 45, no. 4, pp. S490S498, 2003.

[19] C. G. Victora, L. Adair, C. Fall et al., "Maternal and child undernutrition: consequences for adult health and human capital," The Lancet, vol. 371, no. 9609, pp. 340-357, 2008.

[20] T. Shafir, R. Angulo-Barroso, J. Su, S. W. Jacobson, and B. Lozoff, "Iron deficiency anemia in infancy and reach and grasp development," Infant Behavior and Development, vol. 32, no. 4, pp. 366-375, 2009.

[21] L. Manning, M. Laman, A. Rosanas-Urgell et al., "Severe anemia in papua new guinean children from a malaria-endemic area: a case-control etiologic study," PLoS Neglected Tropical Diseases, vol. 6, no. 12, Article ID e1972, 2012.

[22] T. Birhane, S. Shiferaw, S. Hagos, and K. S. Mohindra, "Urban food insecurity in the context of high food prices: a community based cross sectional study in Addis Ababa, Ethiopia," BMC Public Health, vol. 14, no. 1, article 680, 2014.

[23] R. E. Black, C. G. Victora, S. P. Walker et al., "Maternal and child undernutrition and overweight in low-income and middleincome countries," The Lancet, vol. 382, no. 9890, pp. 427-451, 2013.

[24] World Health Organization, Iron Deficiency Anemia Assessment, Prevention and Control: A Guide for Programme Managers, WHO, Geneva, Switzerland, 2001.

[25] World Health Organization, World Health Organization Child Growth Standards: Methods and Development, World Health Organization, Geneva, Switzerland, 2006.

[26] World Health Organization, Indicators for Assessing Infant and Young Child Feeding Practices, WHO Press, Geneva, Switzerland, 2010.

[27] M. K. Uddin, M. H. Sardar, M. Z. Hossain et al., "Prevalence of anaemia in children of 6 months to 59 months in Narayanganj, Bangladesh," Journal of Dhaka Medical College, vol. 19, no. 2, pp. 126-130, 2011.

[28] Ministry of Health and Population (MOHP), New ERA, and ICF International, Nepal Demographic and Health Survey 2011, Ministry of Health and Population, Kathmandu, Nepal; New ERA, and ICF International, Calverton, Md, USA, 2012.

[29] Ghana Statistical Service (GSS), Ghana Health Service (GHS), and ICF Macro, Ghana Demographic and Health Survey 2013: Key Findings, GSS, GHS, and ICF Macro, Calverton, Md, USA, 2013.

[30] A. W. Onyango, "Dietary diversity, child nutrition and health in contemporary African communities," Comparative Biochemistry and Physiology, vol. 136, pp. 61-69, 2003.

[31] D. Schellenberg, J. R. M. A. Schellenberg, A. Mushi et al., "The silent burden of anaemia in Tanzanian children: a communitybased study," Bulletin of the World Health Organization, vol. 81, no. 8, pp. 581-590, 2003.

[32] L. P. Leal, M. B. Filho, P. I. C. de Lira, J. N. Figueiroa, and M. M. Osório, "Prevalence of anemia and associated factors in children aged 6-59 months in Pernambuco, Northeastern Brazil," Revista de Saúde Pública, vol. 45, no. 3, pp. 457-466, 2011.

[33] C. M. Chaparro, "Setting the stage for child health and development: prevention of iron deficiency in early infancy," Journal of Nutrition, vol. 138, no. 12, pp. 2529-2533, 2008.

[34] M. M. Black, A. M. Quigg, K. M. Hurley, and M. R. Pepper, "Iron deficiency and iron-deficiency anemia in the first two years of life: strategies to prevent loss of developmental potential," Nutrition Reviews, vol. 69, supplement 1, pp. S64-S70, 2011.

[35] S. R. D. M. Saldiva, S. I. Venancio, A. G. C. Gouveia, A. L. D. S. Castro, M. M. L. Escuder, and E. R. J. Giugliani, "Regional influence on early consumption of foods other than breast milk in infants less than 6 months of age in Brazilian State capitals and the Federal District," Cadernos de Saude Publica, vol. 27, no. 11, pp. 2253-2262, 2011.

[36] F. A. Oski and S. A. Landaw, "Inhibition of iron absorption from human milk by baby food," The American Journal of Diseases of Children, vol. 134, no. 5, pp. 459-460, 1980.

[37] J. K. Meinzen-Derr, M. L. Guerrero, M. Altaye, H. OrtegaGallegos, G. M. Ruiz-Palacios, and A. L. Morrow, "Risk of infant 
anemia is associated with exclusive breast-feeding and maternal anemia in a Mexican cohort," Journal of Nutrition, vol. 136, no. 2, pp. 452-458, 2006.

[38] G. Wiseman, Nutrition and Health, Taylor \& Francis e-Library, New York, NY, USA, 2004.

[39] P. S. Mamiro, P. Kolsteren, D. Roberfroid, S. Tatala, A. S. Opsomer, and J. H. van Camp, "Feeding practices and factors contributing to wasting, stunting, and iron-deficiency anaemia among 3-23-month old children in Kilosa district, rural Tanzania," Journal of Health, Population and Nutrition, vol. 23, no. 3, pp. 222-230, 2005.

[40] World Health Organization and Working Group on Infant and Young Child Feeding Indicators, Developing and Validating Simple Indicators of Dietary Quality and Energy Intake of Infants and Young Child in Developing Countries, World Health Organization, Washington, DC, USA, 2007.

[41] R. D. Semba, S. de Pee, M. O. Ricks, M. Sari, and M. W. Bloem, "Diarrhea and fever as risk factors for anemia among children under age five living in urban slum areas of Indonesia," International Journal of Infectious Diseases, vol. 12, no. 1, pp. 6270, 2008.

[42] C. T. Howard, S. de Pee, M. Sari, M. W. Bloem, and R. D. Semba, "Association of diarrhea with anemia among children under age five living in rural areas of Indonesia," Journal of Tropical Pediatrics, vol. 53, no. 4, pp. 238-244, 2007.

[43] M. M. Osório, P. I. C. Lira, M. Batista-Filho, and A. Ashworth, "Prevalence of anemia in children 6-59 months old in the state of Pernambuco, Brazil," Revista Panamericana de Salud Pública, vol. 10, no. 2, pp. 101-107, 2001.

[44] A. Zhao, Y. Zhang, Y. Peng et al., "Prevalence of anemia and its risk factors among children 6-36 months old in Burma," The American Journal of Tropical Medicine and Hygiene, vol. 87, no. 2, pp. 306-311, 2012.

[45] A. T. Soliman, M. M. Al dabbagh, A. H. Habboub, A. Adel, N. A. Humaidy, and A. Abushahin, "Linear growth in children with iron deficiency anemia before and after treatment," Journal of Tropical Pediatrics, vol. 55, no. 5, Article ID fmp011, pp. 324-327, 2009.

[46] Factors associated with Hemoglobin concentration among Timor-Leste children Aged 6-59 months, Australia, 2009.

[47] D. Ali, K. K. Saha, P. H. Nguyen et al., "Household food insecurity is associated with higher child undernutrition in Bangladesh, Ethiopia, and Vietnam, but the effect is not mediated by child dietary diversity," Journal of Nutrition, vol. 143, no. 12, pp. 2015-2021, 2013. 


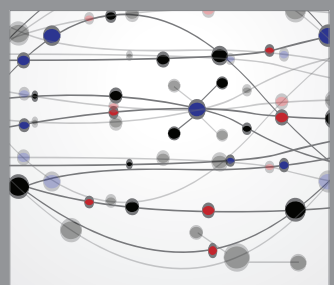

The Scientific World Journal
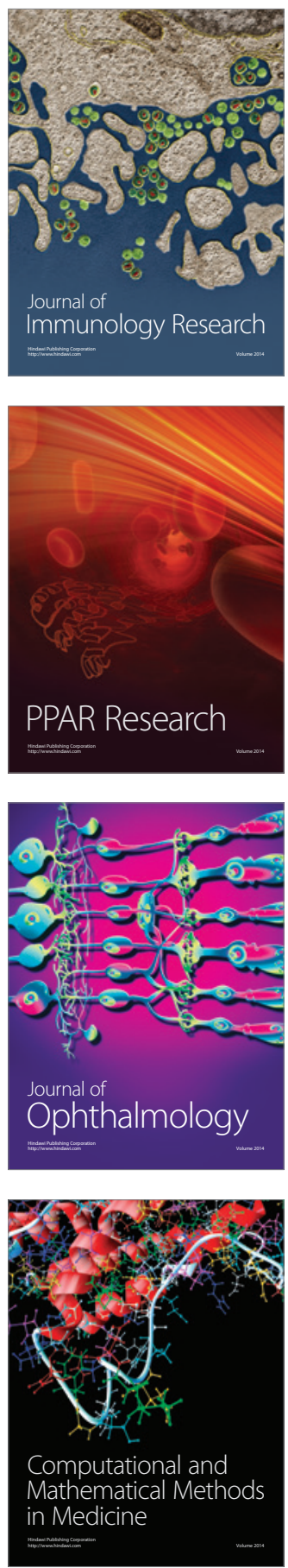

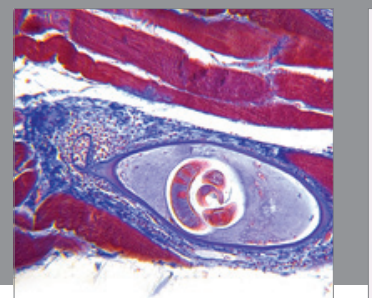

Gastroenterology

Research and Practice
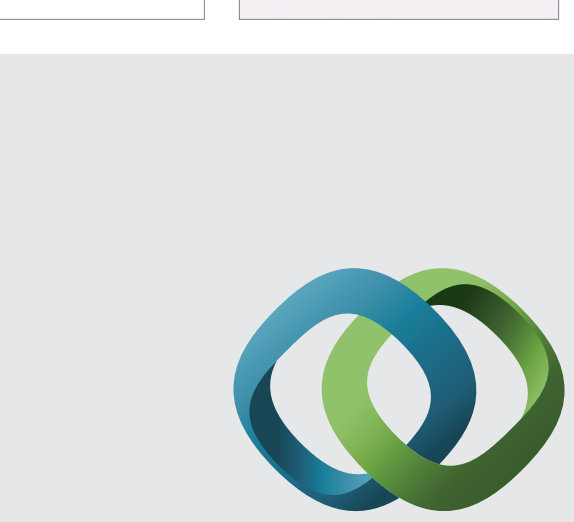

\section{Hindawi}

Submit your manuscripts at

http://www.hindawi.com
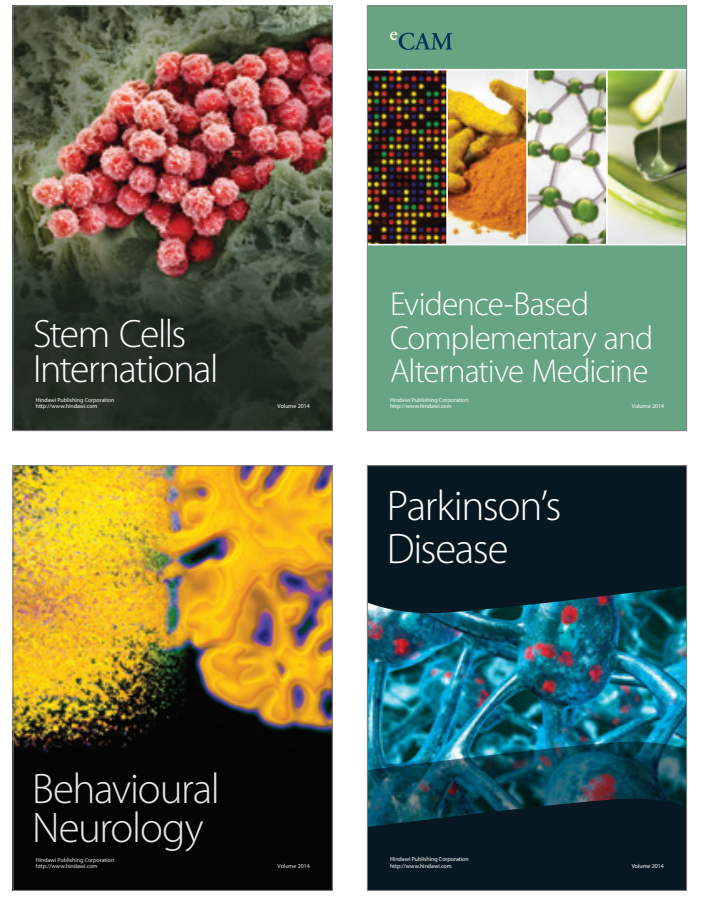
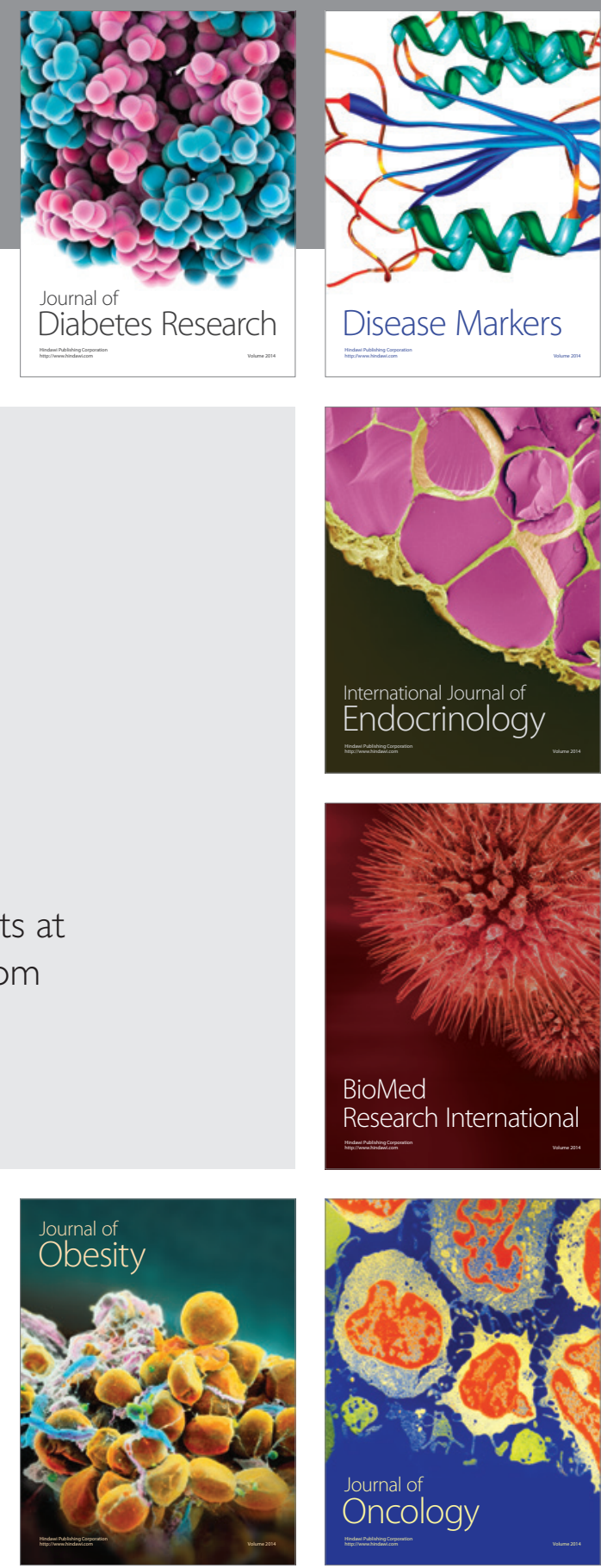

Disease Markers
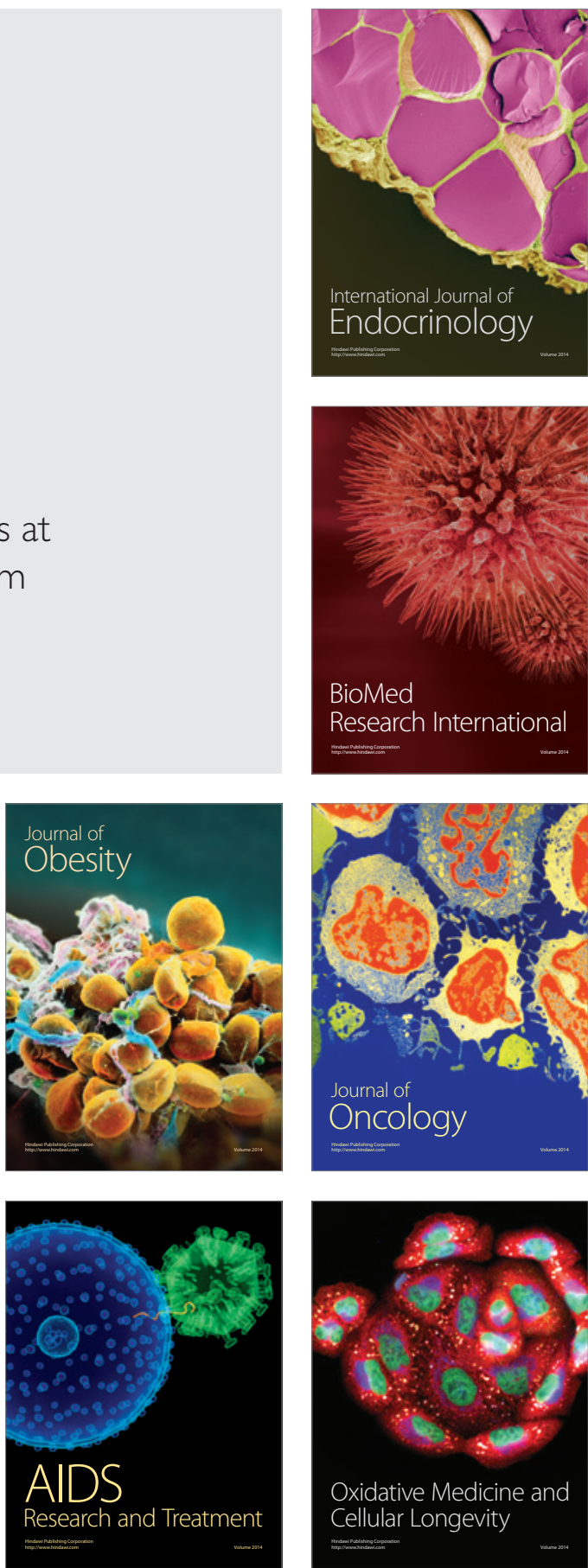